\title{
PENGENDALIAN KUALITAS PRODUK KOPI SS DI PT. SJ
}

\author{
Ika Widya Ardhyani ${ }^{1}$, Moch. Aris Ariyanto ${ }^{2}$
}

\author{
Fakultas Teknik, Teknik Industri \\ Universitas Maarif Hasyim Latif, Sidoarjo, Indonesia \\ e-mail: 1ika_widya@dosen.umaha.ac.id,2aris_ariyanto@gmail.com
}

Diterima: 24 April 2020. Disetujui : 20 Juni 2020. Dipublikasikan : 30 Juni 2020

(C)2020 -TESJ Fakultas Teknik Universitas Maarif Hasyim Latif. Ini adalah artikel dengan

akses terbuka di bawah lisensi CC BY 4.0 (https://creativecommons.org/licenses/by/4.0/)

\begin{abstract}
ABSTRAK
PT. SJ merupakan perusahaan yang memproduksi biji kopi sangrai. Salah satu merek unggulannya adalah kopi SS. Namun, dalam proses produksi kopi SS masih ditemukan cacat produk. Oleh karena itu, PT. SJ perlu melakukan pengendalian kualitas agar dapat meminimalkan cacat produk tersebut. Metode six sigma sering digunakan oleh perusahaan dalam pengendalian kualitas produk dengan meminimasi jumlah defect. Berdasarkan hasil pengolahan data diketahui jika proses produksi kopi SS memiliki kapabilitas proses yang masih rendah. Tampak pada nilai DPMO yang masih cukup tinggi, yaitu 50,415 dalam satu juta kesempatan. Serta diketahui jenis cacat yang paling dominan pada produk kopi SS adalah cacat pada rasa yaitu sebesar $56 \%$. Maka diberikan usulan perbaikan pada faktor mesin, manusia, metode, dan material agar meminimalkan cacat produk kopi SS PT. SJ.
\end{abstract}

Kata kunci: cacat produk, dpmo, six sigma

\section{PENDAHULUAN}

PT. SJ merupakan sebuah perusahaan yang bergerak dalam bidang pengolahan biji kopi sangrai. Ada beberapa macam merek kopi sangrai dari PT. SJ yang banyak disukai masyarakat dan menjadi produk unggulan dari perusahaan. Hal ini dikarenakan kualitas dari bahan baku kopi PT. SJ yang merupakan kopi dengan kualitas yang terbaik. Salah satu merek kopi unggulan di PT. SJ adalah kopi SS. Kopi sangrai SS yang dihasilkan PT. SJ mampu memenuhi sebagian besar permintaan pasar kopi di daerah Mojokerto, Madura, Jombang, Kediri dan sekitarnya karena kualitas kopi yang dihasilkan.

Namun, dalam proses produksi kopi SS masih terdapat kesalahan serta kecacatan pada produk yang dihasilkan. Kecacatan yang sering terjadi adalah pada warna, kemasan dan rasa kopi yang diproduksi. Cacat produk bisa menimbulkankan produk yang tidak sesuai dengan standar perusahaan. Permasalahan seperti ini harus segera ditindak lanjuti secara cepat dan optimal untuk menjaga kualitas produk.

Kualiatas memiliki pengertian yang cukup luas, sehingga arti dari kualitas mempunyai banyak kriteria dan sangat berpengaruh dari hasil penilaian kepuasan para konsumen. Hal ini timbul dari sikap konsumen yang menginginkan barang dengan kualitas yang terjamin dan semakin ketatnya persaingan antara perusahaan yang sejenis. Maka dari itu pihak perusahaan perlu mengambil kebijaksanaan untuk menjaga kualitas produknya agar diterima konsumen dan dapat bersaing dengan produk sejenis dari perusahaan lain, serta dalam rangka menunjang program jangka panjang perusahaan yaitu mempertahankan pasar yang telah ada atau menambah pasar perusahaan.

Metode pengendalian kualitas sangat penting untuk diterapkan suatu perusahaan demi menghasilkan produk berkualitas dan sesuai dengan standar yang ditentukan oleh produsen dan pasar. Dimana produk yang berkualitas diharapkan dapat bersaing dengan produk-produk unggulan perusahaan-perusahaan kompetitor dengan harga yang lebih kompetitif.

Menurut (Caesaron \& Simatupang, 2015), metode six sigma sering digunakan oleh perusahaan dalam pengendalian kualitas produk dengan meminimasi jumlah defect. Aplikasi six sigma berfokus pada cacat dan variasi, dimulai dengan mengidentifikasi unsur-unsur kritis terhadap kualitas (critical to quality) dari suatu proses hingga memberikan usulan-usulan perbaikan (improvement) terkait cacat yang timbul. Langkah mengurangi cacat dan variasi dilakukan secara sistematis dengan mendefinisikan, mengukur, menganalisa, memperbaiki, dan mengendalikannya.

Berdasarkan hal tersebut, untuk mengurangi tingkat kecacatan dari produk kopi SS di PT. SJ, maka dalam penelitian ini akan dilakukan pengendalian kualitas pada proses produksi kopi 
dengan metode six sigma DMAI (Define, Measure, Analsys, Improve).

\section{METODE PENELITIAN}

Penelitian ini dilakukan atas beberapa tahap, yaitu tahap identifikasi masalah dan tahap pengolahan data.

\section{Tahap Identifikasi Masalah}

Data-data yang diperoleh merupakan data proses produksi yang diperoleh dari pengamatan langsung terhadap hasil produksi. Data yang diperoleh terdiri dari jumlah produksi Januari April 2017, data jumlah produk cacat kopi SS, dan data Critical to Quality (CTQ) yaitu bagian atau atribut yang merupakan elemen dari suatu produk yang berdampak langsung pada kualitas produk dan kepuasan pelanggan.

\section{Tahap Pengolahan Data}

Pengolahan data dilakukan dengan menggunakan prosedur Six Sigma-DMAI :

1. Define- langkah operasional pertama dalam program peningkatan kualitas Six Sigma (Gaspersz, 2002). Tahap ini dilakukan untuk menentukan hal-hal kritis yang diperhatikan oleh konsumen. Pada tahap ini dilakukan pendeskripsian proses produksi, pembuatan diagram SIPOC (Supplier-Input-Process-OutputCustomer) dan penentuan CTQ (Critical to Quality).

2. Measure- merupakan langkah operasional kedua yang bertujuan mengevaluasi dan memahami kondisi proses saat ini di PT SJ. Pada tahap ini dilakukan pengumpulan dan pengolahan data sebelum dilakukan perbaikan, pembuatan peta kendali $\mathrm{p}$ untuk mengetahui apakah proses terkendali baik dari sisi proporsi produk cacat, maupun banyaknya cacat, dan perhitungan DPMO dan sigma quality level.

3. Analyze- pada tahap analyze dilakukan pembuatan diagram pareto untuk mengetahui prioritas cacat yang diperbaiki. Selain itu juga dibuat diagram tulang ikan untuk mengetahui hubungan sebab akibat dari suatu permasalahan.

4. Improve- pada tahap ini dirancang usulanusulan perbaikan untuk mengurangi cacat yang terjadi. Pada tahap ini pula dilakukan implementasi usulan-usulan yang telah dirancang.

\section{HASIL DAN PEMBAHASAN}

PT. SJ adalah suatu perusahaan yang bergerak dalam bidang pengolahan biji kopi mentah yang diolah menjadi produk kopi sangrai (goreng) yang berkualitas. Ada beberapa jenis merek kopi sangrai yang diproduksi dari perusahaan ini yakni kopi dengan merek Mikrolet, SPA, AW dan SS. Semua jenis merek kopi dari perusahaan ini menggunakan bahan baku berupa kopi murni 100\%. Kopi dengan merek SS merupakan produk unggulan PT. SJ.

\section{Proses Produksi Kopi SS \\ Proses Sortasi}

Bahan baku biji kopi diperoleh dari pihak pemasok, masuk ke gudang. Biji kopi mentah dimasukkan ke dalam mesin sortir, berfungsi untuk memisahkan biji kopi mentah dari batu, kayu, plastik serta berbagai benda lain yang tidak diinginkan.

\section{Proses Penggorengan}

Biji kopi mentah digoreng menggunakan mesin goreng yang berbentuk semacam tungku besar dengan menggunakan kompor api berbahan bakar gas. Penggorengan hanya mampu melakukan satu kali penggorengan untuk satu karung biji kopi kapasitas rata-rata $80 \mathrm{~kg}$. Suhu dalam proses penggorengan sampai biji kopi benar-benar matang berkisar antara 200cc-230cc. Waktu yang digunakan setiap kali proses penggorengan yaitu 7-9 menit. Biji kopi yang matang kemudian diberi air untuk mengurangi panas $( \pm 20$ detik), setelah itu kopi akan didinginkan terlebih dahulu di dalam kotak pendingin.

\section{Proses Ayakan Batu}

Biji kopi hasil penggorengan yang sudah matang, terkadang belum benar-benar bersih dari batu atau benda yang tidak diinginkan lainnya ketika proses penggorengan. Biji kopi dimasukkan ke dalam mesin ayak batu dengan cara diangkat menggunakan mesin crane. Pada proses ini biji kopi akan terhisap otomatis oleh mesin sehingga biji kopi bisa terpisah dari batu atau benda yang tidak diinginkan lainnya.

\section{Proses Mixing}

Dalam tahap ini, proses penuangan biji kopi ke dalam mesin mixer Adapun komposisi bahan baku produk kopi SS adalah $50 \%$ biji kopi DF dan $50 \%$ biji kopi 20/25. Biji kopi dituang ke dalam bak besi yang berkapasitas $80 \mathrm{~kg}$. Setelah itu bak-bak tersebut diangkat menggunakan mesin crane untuk dicampur ke dalam mesin khusus campuran. Lama waktu untuk setiap kali campuran adalah sekitar 45 menit.

\section{Proses Pengemasan (Packing)}

Biji kopi masuk kedalam mesin kemas (packing) melalui skrew. Biji kopi yang sudah berada dalam kemasan ditimbang sesuai takaran yang ditentukan, yaitu 250 gram.

\section{Penerapan Pengendalian Kualitas Tahap Mendefinisikan Masalah (Define)}


Tahap ini dilakukan pendefinisian jenis cacat pada produk kopi SS. Terdapat 3 jenis cacat yang sering terjadi pada produk akhir kopi SS, yaitu:

\section{Warna}

Standar warna yang ditentukan perusahaan adalah warna coklat agak kehitaman. Standar warna produk akhir diukur secara visual oleh pihak Quality Control (QC). Cacat produk warna dimana kopi berwarna hitam pekat atau coklat mentah.

\section{Rasa}

Ada dua jenis kopi yang digunakan pada merek kopi SS yaitu jenis kopi DF dan 20/25. Cacat pada rasa terjadi ketika adanya kesalahan dalam jumlah takaran kopi yang telah ditentukan. Selain itu karena biji kopi yang gosong sehingga terasa lebih pahit. Cacat rasa juga disebabkan karena pemberian air yang berlebih setelah proses penggorengan, sehingga menyebabkan kopi terasa ampang dan tidak enak.

3. Kemasan.

Kemasan yang cacat meliputi dari kemasan yang bocor, sobek atau terlipat.

Berdasarkan pada permasalahan yang ada, pada Tabel 1 dijelaskan jumlah produksi dan jumlah produk cacat pada produk kopi SS PT. SJ selama bulan Januari sampai dengan April 2017.

Tabel 1. Jumlah Cacat Produk Kopi SS PT. SJ

\begin{tabular}{l|c|c|c|c}
\hline \multirow{2}{*}{ Bulan } & \multirow{2}{*}{$\begin{array}{c}\text { Jumlah total } \\
\text { produksi (pcs) }\end{array}$} & \multicolumn{3}{|c}{ Jenis produk cacat (pcs) } \\
\cline { 3 - 5 } & & Warna & Rasa & Kemasan \\
\hline Januari & 384085 & 19840 & 31040 & 5605 \\
\hline Februari & 358780 & 18880 & 31680 & 5820 \\
\hline Maret & 399620 & 20160 & 32960 & 6300 \\
\hline April & 371285 & 19200 & 31680 & 5405 \\
\hline
\end{tabular}

\section{Tahap Pengukuran (Measure)}

- Analisis Diagram Kontrol Pengukuran ini dilakukan dengan menggunakan diagram kontrol jenis P-Chart.

Mean $(C L)$ atau rata-rata produk akhir bisa dihitung dengan cara sebagai berikut:

$$
C L=\frac{\sum n p}{\sum n}
$$

Jumlah proporsi produk akhir mingguan $(P)$, produk akhir $(n p)$ dibagi dengan sampel $(n)$ :

$$
P=\frac{n p}{n}
$$

Jumlah batas kendali atas (UCL)

$$
U C L=p+3 \frac{\sqrt{p(1-p))}}{n}
$$

Jumlah batas kendali bawah $(L C L)$

$$
L C L=p-3 \frac{\sqrt{p(1-p)}}{n}
$$

Berdasarkan hasil peta kendali $\mathrm{P}$ dapat disimpulkan bahwa hampir $70 \%$ data berada diluar batas kendali. Hal ini menunjukkan bahwa kapabilitas proses tidak berjalan dengan baik, sehingga perlu dilakukan pengendalian kualitas pada PT. SJ khususnya produk SS.

- Tahap Pengukuran Defect Per Million Opportunities (DPMO) dan Tingkat Sigma

Penentuan CTQ (Critical to Quality), pada proses produksi kopi SS karakteristik yang menyebabkan hasil produksi tidak memenuhi harapan pelanggan atau konsumen adalah warna biji kopi yang tidak sesuai, rasa yang tidak sesuai, serta kemasan yang tidak.

\section{Menghitung Defect per Unit (DPU)}

$$
D P U=\frac{\text { Totalkerusakan }}{\text { Totalproduksi }}
$$

Menghitung Defect Per Opportunity (DPO)

$$
D P O=\frac{D P U}{\text { BanyakCTQ }}
$$

\section{Menghitung Defect Per Million Opportunities} (DPMO)

$$
D P M O=D P O \times 1.000 .000
$$

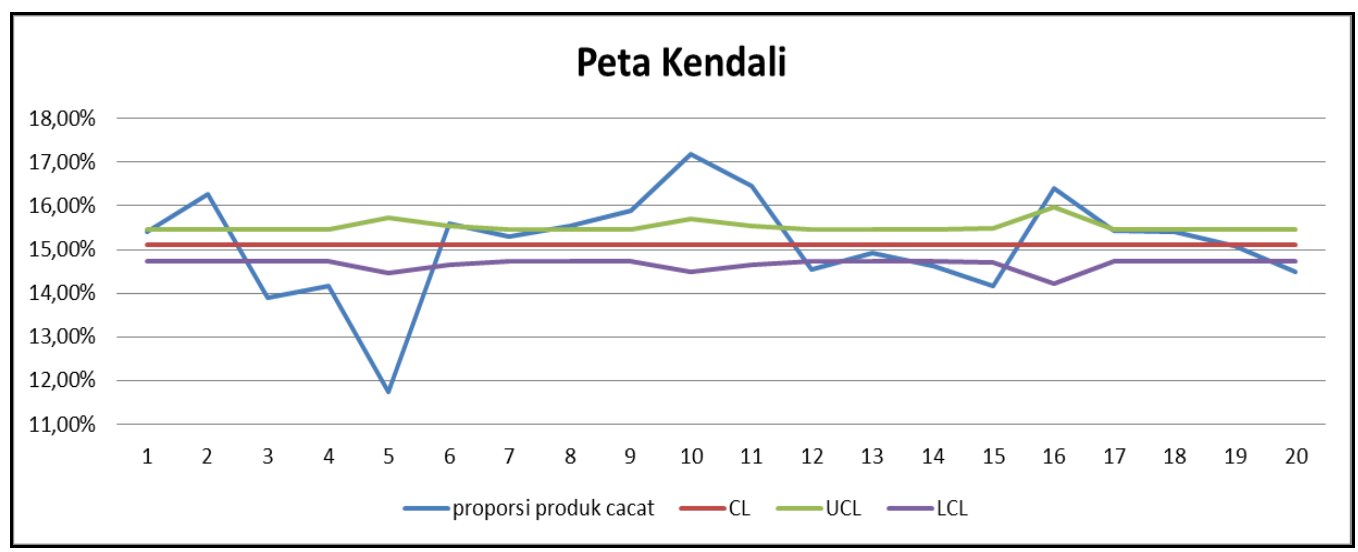

Gambar 1. Peta Kendali P Produk Kopi SS 
Tabel 2. Kapabilitas Sigma, DPMO dari Proses Pembuatan Kopi SS bulan Januari-April 2017

\begin{tabular}{l|c|c|c|c|c|c|c}
\hline \multicolumn{1}{c}{ Bulan } & $\begin{array}{c}\text { Jumlah } \\
\text { Produksi }\end{array}$ & $\begin{array}{c}\text { Jumlah Produk } \\
\text { cacat }\end{array}$ & $\begin{array}{c}\text { Tingkat cacat } \\
\text { (DPU) }\end{array}$ & $\begin{array}{c}\text { Banyak } \\
\text { CTQ }\end{array}$ & (DPO) & DPMO & $\begin{array}{c}\text { Nilai } \\
\text { Sigma }\end{array}$ \\
\hline I/Januari & 89370 & 13770 & 0,154 & 3 & 0,0514 & 51400 & 3,1 \\
\hline II/Januari & 90285 & 14685 & 0,163 & 3 & 0,0542 & 54200 & 3,1 \\
\hline III/Januari & 87795 & 12195 & 0,139 & 3 & 0,0463 & 46300 & 3,2 \\
\hline IV/Januari & 88085 & 12485 & 0,142 & 3 & 0,0472 & 47200 & 3,2 \\
\hline V/Januari & 28550 & 3350 & 0,117 & 3 & 0,0391 & 39100 & 3,3 \\
\hline I/Februari & 59710 & 9310 & 0,156 & 3 & 0,0520 & 52000 & 3,1 \\
\hline II/Febuari & 89250 & 13650 & 0,153 & 3 & 0,0510 & 51000 & 3,1 \\
\hline III/Februari & 89520 & 13920 & 0,155 & 3 & 0,0518 & 51800 & 3,1 \\
\hline IV/Februari & 89870 & 14270 & 0,159 & 3 & 0,0529 & 52900 & 3,1 \\
\hline V/Februari & 30430 & 5230 & 0,172 & 3 & 0,0573 & 57300 & 3,1 \\
\hline I/Maret & 60330 & 9930 & 0,165 & 3 & 0,0549 & 54900 & 3,1 \\
\hline II/Maret & 88480 & 12880 & 0,146 & 3 & 0,0485 & 48500 & 3,2 \\
\hline III/Maret & 88850 & 13250 & 0,149 & 3 & 0,0497 & 49700 & 3,1 \\
\hline IV/Maret & 88550 & 12950 & 0,146 & 3 & 0,0487 & 48700 & 3,2 \\
\hline V/Maret & 73410 & 10410 & 0,142 & 3 & 0,0473 & 47300 & 3,2 \\
\hline I/April & 15070 & 2470 & 0,164 & 3 & 0,0546 & 54600 & 3,1 \\
\hline II/April & 89405 & 13805 & 0,154 & 3 & 0,0515 & 51500 & 3,1 \\
\hline III/April & 89370 & 13770 & 0,154 & 3 & 0,0514 & 51400 & 3,1 \\
\hline IV/April & 89015 & 13415 & 0,151 & 3 & 0,0502 & 50200 & 3,1 \\
\hline V/April & 88425 & 12825 & 0,145 & 3 & 0,0483 & 48300 & 3,2 \\
\hline Jumlah & 1513770 & 228570 & 63,025 & & 1,0084 & 1008300 & 62,8 \\
\hline
\end{tabular}

Dari hasil perhitungan dalam Tabel 2 dapat diketahui bahwa proses produksi kopi SS memiliki kapabilitas proses yang masih rendah. Tampak pada DPMO yang masih cukup tinggi, yaitu 50.415, yang dapat diartikan bahwa dalam satu juta kesempatan yang ada, masih terdapat 50.415 kemungkinan bahwa proses produksi itu akan menghasilkan produk cacat. Maka pengendalian kualitas harus terus ditingkatkan, agar menunjukkan pola DPMO kecacatan produk yang terus-menerus menurun sepanjang waktu dan pola kapabilitas Sigma yang meningkat terus menerus. Tingkat kecacatan yang tinggi dapat menimbulkan kerugian yang besar terhadap perusahaan.

\section{Tahap Analisis (Analyze)}

Tabel 3 menunjukkan persentase jumlah kecacatan dan persentase kumulatif kopi SS.

\section{Tahap Improve}

Pada tahap ini diberikan usulan perbaikan untuk peningkatan kualitas. Berdasarkan hasil diagram pareto pada Gambar 2, diketahui jenis cacat yang paling dominan adalah rasa yang tidak sesuai sebesar 56\%. Sehingga. pada Tabel 4 diberikan usulan perbaikan untuk menekan cacat produk rasa, agar dapat meningkatkan kualitas produk SS PT. SJ.

Tabel 3. Hasil Perhitungan Persentase Cacat dan persentase Kumulatif Kopi SS

\begin{tabular}{c|c|c|c|c}
\hline No. & $\begin{array}{c}\text { Jenis } \\
\text { Cacat }\end{array}$ & $\begin{array}{c}\text { Jumlah } \\
\text { Cacat }\end{array}$ & Persentase & $\begin{array}{c}\text { Persentase } \\
\text { Kumulatif }\end{array}$ \\
\hline 1. & Rasa & 127360 & $56 \%$ & $56 \%$ \\
\hline 2. & Warna & 78080 & $34 \%$ & $90 \%$ \\
\hline 3. & Kemasan & 23130 & $10 \%$ & $100 \%$ \\
\hline & Total & $\mathbf{2 2 8 5 7 0}$ & $\mathbf{1 0 0 \%}$ & \\
\hline
\end{tabular}

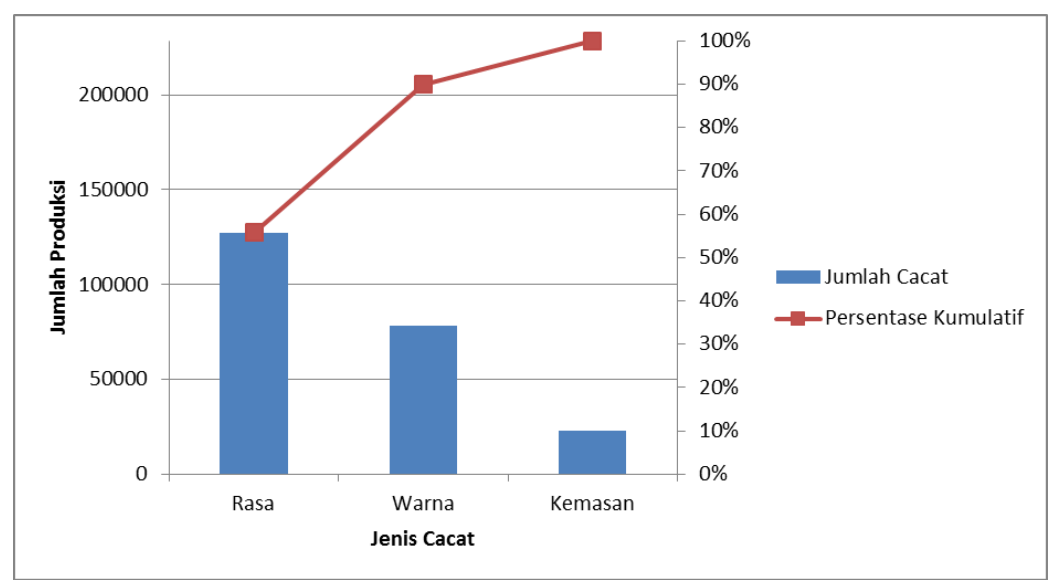

Gambar 2. Diagram Pareto Jenis Cacat Produk Pada Kopi SS 
Tabel 4. Usulan Tidakan Perbaikan Pada Cacat Rasa

\begin{tabular}{|c|c|c|}
\hline Faktor & Faktor Penyebab & Usulan Tindakan Perbaikan \\
\hline Mesin & $\begin{array}{l}\text { 1. Perputaran mesin pada Mixer lambat, tidak } \\
\text { sesuai dengan standar kecepatan nomal. PT. } \\
\text { SJ melakukan perbaikan mesin hanya pada } \\
\text { saat terjadi kerusakan pada mesin. }\end{array}$ & $\begin{array}{l}\text { 1. Mengganti komponen yang sudah aus. } \\
\text { 2. Membuat jadwal perawatan mesin, secara } \\
\text { rutin. }\end{array}$ \\
\hline Manusia & $\begin{array}{l}\text { 1. Asal tuang takaran, dimana pekerja } \\
\text { menuangkan bahan baku kopi tidak sesuai } \\
\text { dengan komposisi yang ditentukan oleh } \\
\text { perusahaan. } \\
\text { 2. Lalai dalam bekerja, dimana proses } \\
\text { pencampuran kurang dari waktu standar } \\
\text { perusahaan (yaitu kurang dari } 4 \text { menit), } \\
\text { kurang memperhatikan instruksi kerja } \\
\text { perusahaan. }\end{array}$ & $\begin{array}{l}\text { 1. Instruksi dan koordinasi kerja diberikan oleh } \\
\text { atasan melalui briefing singkat dan tertulis } \\
\text { pada area kerja. } \\
\text { 2. Dilakukan training untuk karyawan baru. } \\
\text { 3. Peringatan dan sanksi tegas terhadap } \\
\text { pelanggaran yang dilakukan (misal: pemberian } \\
\text { surat peringatan, skorsing, pemotongan gaji, } \\
\text { hingga pemecatan) }\end{array}$ \\
\hline Metode & $\begin{array}{l}\text { 1. Pengawasan belum efektif, dimana kepala } \\
\text { bagian yang bertugas melaksanakan } \\
\text { inspeksi kurang melakukan pengawasan } \\
\text { terhadap pekerja bagian pencampuran. } \\
\text { 2. Kurang mentaati SOP atau intruksi kerja. }\end{array}$ & $\begin{array}{l}\text { 1. Menambah jumlah CCTV pada setiap area yang } \\
\text { penting, untuk mempermudah pengawasan. } \\
\text { 2. Menambah motivasi kerja karyawan. } \\
\text { 3. Memberikan bonus bagi karyawan yang } \\
\text { bekerja dengan disiplin dan sesuai standar } \\
\text { perusahaan. }\end{array}$ \\
\hline Material & $\begin{array}{l}\text { 1. Gosong atau mentah, disebabkan karena } \\
\text { hasil proses penggorengan biji kopi tidak } \\
\text { sempurna. } \\
\text { 2. Terlalu banyak air, hal ini disebabkan } \\
\text { setelah penggorengan (tujuan memberikan } \\
\text { air adalah untuk menurunkan suhu biji kopi } \\
\text { setelah proses penggorengan). }\end{array}$ & $\begin{array}{l}\text { 1. Dilakukan inspeksi secara ketat setelah biji } \\
\text { kopi diproses dalam penggorengan. } \\
\text { 2. Mentaati intruksi kerja yang sudah tertera di } \\
\text { area kerja. }\end{array}$ \\
\hline
\end{tabular}

\section{PENUTUP}

Proses produkai kopi SS memiliki kapabilitas proses yang masih rendah. Tampak pada nilai DPMO yang masih cukup tinggi, yaitu 50.415 dalam satu juta kesempatan.

Berdasarkan pengolahan dan analisis data diketahui jenis cacat yang paling dominan pada produk kopi SS adalah cacat pada rasa yaitu sebesar $56 \%$.

Faktor-faktor yang mempengaruhi terjadinya cacat pada rasa pada produk kopi SS, perputaran mesin pada Mixer lambat, tidak sesuai dengan standar kecepatan normal, asal tuang takaran dimana pekerja menuangkan bahan baku kopi tidak sesuai dengan komposisi yang ditentukan oleh perusahaan, lalai dalam bekerja, dimana proses pencampuran kurang dari waktu standar perusahaan (yaitu kurang dari 4 menit), kurang memperhatikan instruksi kerja perusahaan, pengawasan belum efektif, dimana kepala bagian yang bertugas melakukan inspeksi kurang melakukan pengawasan terhadap pekerja bagian pencampuran, kurang mentaati SOP atau intruksi kerja, gosong atau mentah disebabkan karena hasil proses penggorengan biji kopi mentah tidak sempurna, terlalu banyak air, hal ini disebabkan proses setelah penggorengan (untuk menurunkan suhu biji kopi setelah proses penggorengan).

\section{DAFTAR PUSTAKA}

Buffa, E. W. (1989). Manajemen Produksi dan Operasi (Edisi Keen). Jakarta: Erlangga.

Caesaron, D., \& Simatupang, S. Y. P. (2015). Implementasi pendekatan DMAIC untuk perbaikan proses produksi pipa PVC (studi kasus PT. Rusli Vinilon). Jurnal Metris, 16(2), 91-96.

Ekoanindiyo, F. A. (2014). Pengendalian Cacat Produk Dengan Pendekatan Six Sigma. Jurnal Ilmiah Dinamika Teknik, 8(1), 35-43.

Gaspersz, V. (2002). Pedoman Implementasi Program Six Sigma: Terintegrasi Dengan ISO 9001 dan HACCP. PT. Gramedia Pustaka Tama.

Gaspersz, V. (2006). Total Quality Managemen Untuk Praktisi Bisnis dan Industri. Jakarta: PT. Gramedia Pustaka Utama. 
IW Ardhyani, dkk / Teknika : Engineering and Sains Journal, Vol. 4, No.1, Juni 2020, 1-6

halaman ini sengaja dikosongkan 